\title{
Evaluation of heat transfer in humidification phenomena - Comparison between infrared thermography and numerical simulation
}

\author{
Eva Barreira $^{1, *}$, Ricardo M.S.F. Almeida ${ }^{1,2}$, and Miguel Pereira ${ }^{1}$ \\ ${ }^{1}$ CONSTRUCT-LFC, University of Porto, Faculty of Engineering, Department of Civil Engineering, \\ Portugal \\ ${ }^{2}$ Polytechnic Institute of Viseu, Escola Superior de Tecnologia e Gestão de Viseu, Portugal
}

\begin{abstract}
Infrared thermography (IRT) is a non-destructive testing technology used to assess the performance of buildings. As a diagnosis tool for retrofit and conservation of buildings it helps understanding the anomalies by allowing "seeing" their causes in a non-invasive manner. However, in most cases, the interpretation of the results (thermal images) is mainly qualitative, restraining and, eventually, pointing to incorrect conclusions. Using numerical tools that contribute to the quantitative interpretation of IRT applications is therefore a step forward in this field. The main objective of this work is the evaluation of heat transfer in humidification phenomena by comparing the results of $2 \mathrm{D}$ hygrothermal simulation with thermal images. Thermal images were taken to a lightweight concrete specimen during a 24-hours partial immersion period. The humidification of the specimen was simulated using WUFI 2D. The best way to deal with the liquid water level in contact with the bottom of the specimen was deeply analysed. The comparison of the simulation with the results of IRT showed that the program tends to overestimate the phenomena of heat transfer (water rise and evaporation on the surface), as the water level reached in the simulation was consistently higher than the one obtained in the thermal images.
\end{abstract}

\section{Introduction}

Infrared thermography (IRT) is a non-contact and non-destructive testing technology that allows obtaining superficial temperatures of a body by measuring the infrared radiation emitted its surface. The results are thermal images or thermograms, which describe the distributions of temperature based on a colour scale [1].

In the construction industry, this technology has been used to evaluate the thermal behaviour of existing buildings [2] and to identify potential problems, like: insulation defects [3], air leaks [4], thermal bridges [5], defects in façades [6] and moisture in building components [7]. The use of IRT in inspection procedures is well defined in standards such as ISO $6781[8]$.

*Corresponding author: barreira@,fe.up.pt 
Although its several uses for building diagnosis, in most cases, the interpretation of IRT results (thermal images) is mainly qualitative, restraining and, eventually, pointing to incorrect conclusions. Using numerical tools that contribute to the quantitative interpretation of IRT applications is therefore a step forward in this field.

In this work, heat transfer in humidification phenomena is assessed by comparing the results of $2 \mathrm{D}$ hygrothermal simulation with thermal images. The main objective was to define the best way to deal with the liquid water level in contact with the bottom of the specimen, as no specific parameter was requested as input of the software.

\section{Methodology}

As case study, a lightweight concrete specimen (Table 1) was partially humidified by the bottom, during 24 hours, inside a climatic chamber $\left(\mathrm{T}=20^{\circ} \mathrm{C}\right.$; $\left.\mathrm{RH}=60 \%\right)$. A $5 \mathrm{~mm}$ liquid water level was maintained above the bottom of the specimen throughout the test period. Thermal images were taken automatically at 30 minutes, 4 hours, 8 hours e 24 hours (Figure 1). The passive approach was applied and the infrared camera (IR) remained in the same position during the humidification period. Particular attention was given to avoid the effect of reflections during the data acquisition. All compensations imposed by the IR were carried out before the beginning of the test. The specifications of the IR camera are described in [9].

Table 1. Properties of the lightweight concrete specimen.

\begin{tabular}{|c|c|}
\hline Dimensions & $0.28 \mathrm{~m} \mathrm{x} 0.21 \mathrm{~m} \mathrm{x} 0.075 \mathrm{~m}$ \\
\hline Bulk density & $1350.8 \mathrm{~kg} / \mathrm{m}^{3}$ \\
\hline Porosity & $14 \%$ \\
\hline Heat capacity & $1500 \mathrm{~J} /(\mathrm{kgK})$ \\
\hline Thermal conductivity & $0.7 \mathrm{~W} /\left(\mathrm{m}^{2} \mathrm{~K}\right)$ \\
\hline Water vapour resistance factor & 7.4 \\
\hline Emissivity & 0.91 \\
\hline
\end{tabular}

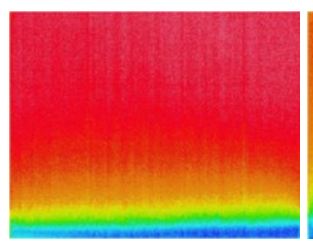

a)

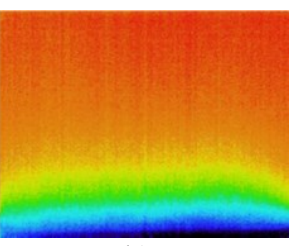

b)

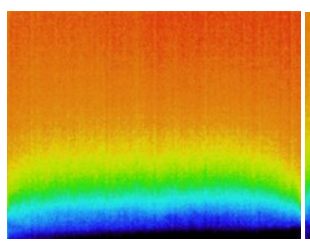

c)

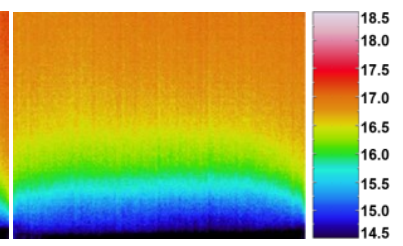

d)

Fig. 1. Thermal images during humidification: a) 30 minutes; b) 4 hours, c) 8 hours; d) 24 hours.

The numerical simulation was carried out using WUFI 2D [10]. The comparison of temperature profiles obtained with WUFI 2D and thermal images was only possible because the intermediate layer provided by the software was converted into surface temperature profiles, which are the results of IRT. This procedure included performing two simulations, one for each vertical section of the specimen (I-longitudinal section and IItransversal section). Simulation I (longitudinal section) resulted in temperature profiles on an intermediate layer of the specimen, parallel to the surface under study. Simulation II 
(transversal section) resulted in temperature profiles perpendicular to the surface under study. To convert inner temperatures (profiles from Simulation I) into surface temperatures (compared with IRT), the information of Simulation II (transversal section) was used. To this end, in profile from Simulation II (transversal section), the temperature at the core (A') (at different heights of the profile) was subtracted from the corresponding outer temperature (A"). The difference between the two (at different heights of the profile) was added to the temperature profile from Simulation I (Figure 2).

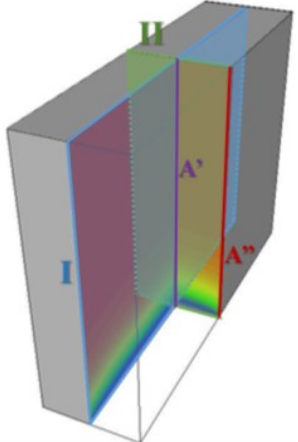

a)

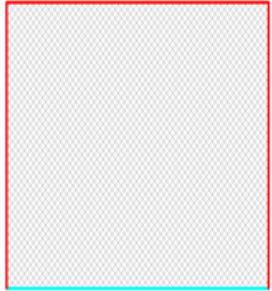

b)

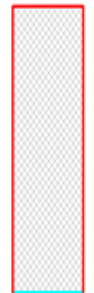

c)

Fig. 2. a) Temperature profiles used in the simulation: I-longitudinal section with temperature profiles parallel to the surface under study; II-transversal section with temperature profiles perpendicular to the surface under study; to convert temperatures from profile I into surface temperatures (compared with IRT), temperature at A' in profile II was subtracted from temperature at A', also in profile II, and the difference was added to the temperature of profile I; b) Boundaries and geometries of the specimen in Simulation I (left) and II (right); c) Location of the temperatures lines used for the comparison in the preliminary simulations.

A set of preliminary simulations was performed to define the best way to deal with the liquid water level in contact with the bottom of the specimen. After that procedure was selected, the boundary conditions were adjusted to the real test conditions, allowing comparing the results of numerical simulation with the thermal images.

The material properties used in the simulation are presented in Table 1. The simulation period was 24 hours with a time step of 5 minutes. The climatic conditions for red boundaries in Figure $2 \mathrm{~b}$ are the same maintained inside the climatic chamber during the humidification period $\left(\mathrm{T}=20^{\circ} \mathrm{C} ; \mathrm{RH}=60 \%\right)$. For the blue boundary (bottom of the specimen in contact with liquid water), the following climatic conditions were considered:

- Simulation S1: interior climate with $\mathrm{RH}=100 \%$ and $\mathrm{T}=20^{\circ} \mathrm{C}$; initial temperature of the specimen of $20^{\circ} \mathrm{C}$.

- Simulation S2: interior climate with $\mathrm{RH}=100 \%$ and $\mathrm{T}=12^{\circ} \mathrm{C}$ (considering that the air near the upper boundaries of the specimen was saturated at the bottom); initial temperature of the specimen of $20^{\circ} \mathrm{C}$.

- Simulation S3: interior climate with $\mathrm{RH}=100 \%$ and $\mathrm{T}=15^{\circ} \mathrm{C}$ (temperature estimated for the water); moisture source of $1.389 \times 10^{-3} \mathrm{~kg} /(\mathrm{ms}$ ) (corresponding to $5 \mathrm{~mm} / \mathrm{h}$ ); initial temperature of the specimen of $20^{\circ} \mathrm{C}$.

- Simulation S4: exterior climate with $\mathrm{RH}=100 \%, \mathrm{~T}=15^{\circ} \mathrm{C}$ (temperature estimated for the water) and wind driven rain corresponding to $5 \mathrm{~mm} / \mathrm{h}$ at the bottom of the specimen; initial temperature of the specimen of $20^{\circ} \mathrm{C}$.

To compare the thermal images with the results obtained considering the four boundary conditions, the temperatures at three different levels were analysed: one at the top, one at the centre and one at bottom (Figure 2c). 


\section{Results}

The temperatures at the top, centre and bottom of the specimen for $\mathrm{t}=30 \mathrm{~min}, \mathrm{t}=4 \mathrm{~h}, \mathrm{t}=8 \mathrm{~h}$ and $t=24 \mathrm{~h}$ obtained by simulation considering the four boundary conditions (S1 to S4) and temperatures of the thermal images are shown in Figure 3. At the top of the specimen, according to the IRT results (TERMO in Figure 3a), temperature was constant along the length of the specimen and during the humidification period: at $\mathrm{t}=30 \mathrm{~min}$ average temperature is $17.7^{\circ} \mathrm{C}$ and at $\mathrm{t}=24 \mathrm{~h}$ average temperature is $17^{\circ} \mathrm{C}$. Considering the results of the simulation, temperatures are always higher than the ones at the thermal image. At $\mathrm{t}=$ $30 \mathrm{~min}$, the temperatures are the same for all boundary conditions ( $\mathrm{S} 1$ to $\mathrm{S} 4)$. Along time (t $=4 \mathrm{~h}, \mathrm{t}=8 \mathrm{~h}$ and $\mathrm{t}=24 \mathrm{~h}$ ), temperatures in $\mathrm{S} 2, \mathrm{~S} 3$ and $\mathrm{S} 4$ decreased and temperature in $\mathrm{S} 1$ increased. One can conclude that at the top of the specimen, temperatures were mostly influenced by the climate conditions considered for the boundaries.

At the centre of the specimen (Figure 3b), there was also a decrease of temperature over time, both in thermal image and in the simulations. Temperatures were lower than the ones achieved at the top, because this level is near the moisture source at the bottom of the specimen. Once more, temperature of the thermal image was constant, but in the simulations, temperatures in the centre were different from the ones at the edges. Results closer to the IRT were achieved by simulation S2. Simulations S3 and S4 delivered similar results.

Figure $3 \mathrm{c}$ shows that the differences between simulations were, at this level, sharper, especially at the end of the simulation. Simulation S2 presented temperature values closer to the thermal image, but simulation S4 presented better results if the evolution over the length of the specimen is considered.

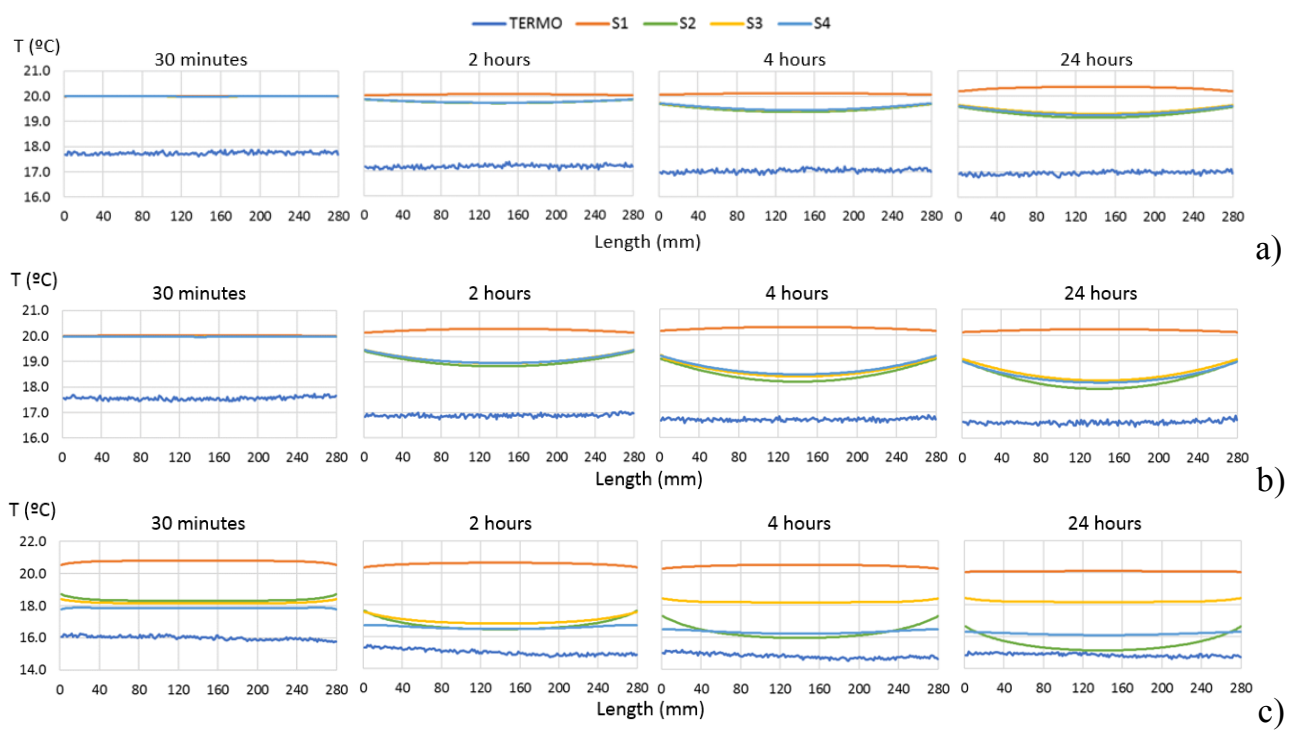

Fig. 3. Temperatures of the specimen for $t=30 \mathrm{~min}, \mathrm{t}=4 \mathrm{~h}, \mathrm{t}=8 \mathrm{~h}$ and $\mathrm{t}=24 \mathrm{~h}$ obtained by simulation considering the four boundary conditions (S1 to S4) and temperatures of the thermal images (TERMO): a) at the top; b) at the centre; c) at the bottom.

Considering that: a) simulation S4 is the one with better results in terms of temperature distribution along the length of the specimen; b) simulation S2 is the one that allowed achieving values closer to the thermal image; and c) the temperature of the specimen and of 
the climatic chamber are not the same at the beginning of the test, that is, the temperature of the specimen is $17.7^{\circ} \mathrm{C}$ (see TERMO in Figure $3 \mathrm{a}$ ) and not $20^{\circ} \mathrm{C}$, new simulations were performed:

- Simulation A: on red boundaries in Figure $2 \mathrm{~b}$ interior climate with $\mathrm{RH}=100 \%$ and $\mathrm{T}=17.7^{\circ} \mathrm{C}$; on blue boundary exterior climate with $\mathrm{RH}=100 \%, \mathrm{~T}=15^{\circ} \mathrm{C}$ (as $\mathrm{S} 4$ ) and wind driven rain equal to $5 \mathrm{~mm} / \mathrm{h}$; initial temperature of the specimen of $17.7^{\circ} \mathrm{C}$.

- Simulation B: on red boundaries in Figure $2 b$ interior climate with $\mathrm{RH}=100 \%$ and $\mathrm{T}=17.7^{\circ} \mathrm{C}$; on blue boundary exterior climate with $\mathrm{RH}=100 \%, \mathrm{~T}=12^{\circ} \mathrm{C}$ (as $\mathrm{S} 2$ ) and wind driven rain corresponding to $5 \mathrm{~mm} / \mathrm{h}$; initial temperature of the specimen of $17.7^{\circ} \mathrm{C}$.

Figure 4 presents the temperatures at the top, centre and bottom of the specimen for $\mathrm{t}=$ $30 \mathrm{~min}, \mathrm{t}=4 \mathrm{~h}, \mathrm{t}=8 \mathrm{~h}$ and $\mathrm{t}=24 \mathrm{~h}$ obtained by simulations $\mathrm{A}$ and $\mathrm{B}$, as well as the temperatures of the thermal images.

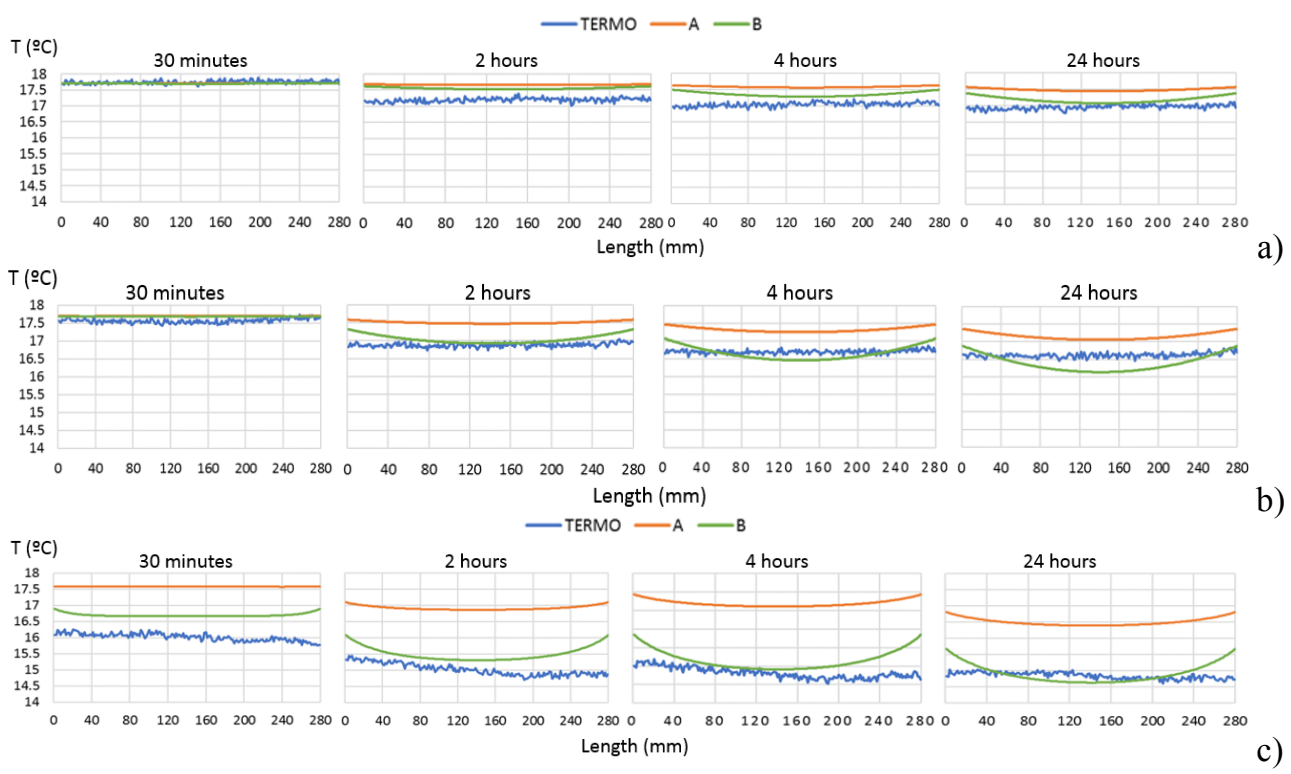

Fig. 4. Temperatures of the specimen for $t=30 \mathrm{~min}, \mathrm{t}=4 \mathrm{~h}, \mathrm{t}=8 \mathrm{~h}$ and $\mathrm{t}=24 \mathrm{~h}$ obtained by simulations $\mathrm{A}$ and $\mathrm{B}$ and temperatures of the thermal images (TERMO): a) at the top; b) at the centre; c) at the bottom.

Both in top and centre of the specimen, the results of simulations A and B are very similar, especially in the beginning. Temperatures are closer to the ones of the thermal images in simulation B, although no relevant differences can indeed be pointed out. When analysing temperatures at the bottom, differences between the two simulations become clearer. In fact, inputting a lower temperature at the boundary in contact with liquid water is crucial to achieve better agreement between the simulation and the thermal images.

Table 2 presents the average of the absolute differences between the simulations (A and $\mathrm{B})$ and the thermal images. The results highlight that indeed simulation $\mathrm{B}$ is the one that provides a better agreement.

These results also show that the program tends to overestimate the phenomena of heat transfer, as the water level reached in the simulation was consistently higher than the one obtained in the thermal images. This occurs not only when water rise is the key parameter (centre of the specimen) but also when evaporation on the surface is the main load of temperature differences at the surface (edges of the specimen). 
Table 2. Average of the absolute differences between the results of simulations (A and $\mathrm{B}$ ) and the thermal images.

\begin{tabular}{|c|c|c|c|}
\hline & & \multicolumn{2}{|c|}{ Average of the absolute differences $\left({ }^{\circ} \mathrm{C}\right)$} \\
\hline & & A vs TERMO & B vs TERMO \\
\hline \multirow{4}{*}{ Top } & $\mathrm{t}=30 \mathrm{~min}$ & 0.06 & 0.06 \\
\hline & $t=4 h$ & 0.47 & 0.36 \\
\hline & $\mathrm{t}=8 \mathrm{~h}$ & 0.54 & 0.31 \\
\hline & $\mathrm{t}=24 \mathrm{~h}$ & 0.53 & 0.22 \\
\hline \multirow{4}{*}{ Centre } & $\mathrm{t}=30 \mathrm{~min}$ & 0.14 & 0.12 \\
\hline & $\mathrm{t}=4 \mathrm{~h}$ & 0.63 & 0.17 \\
\hline & $\mathrm{t}=8 \mathrm{~h}$ & 0.62 & 0.15 \\
\hline & $\mathrm{t}=24 \mathrm{~h}$ & 0.54 & 0.27 \\
\hline \multirow{4}{*}{ Bottom } & $\mathrm{t}=30 \mathrm{~min}$ & 1.56 & 0.68 \\
\hline & $\mathrm{t}=4 \mathrm{~h}$ & 1.90 & 0.48 \\
\hline & $\mathrm{t}=8 \mathrm{~h}$ & 1.88 & 0.34 \\
\hline & $t=24 h$ & 1.66 & 0.23 \\
\hline
\end{tabular}

\section{Conclusions}

A new strategy to deal with the effect of liquid water on surface temperature patterns was proposed in order to compare the results of 2D hygrothermal simulation with thermal images obtained with infrared thermography (IRT). The comparison of the simulation with the results of IRT showed that the program tends to overestimate the phenomena of heat transfer (water rise and evaporation on the surface), as the water level reached in the simulation was consistently higher than the one obtained in the thermal images.

This work was financially supported by: UID/ECI/04708/2019- CONSTRUCT - Instituto de I\&D em Estruturas e Construções funded by national funds through the FCT/MCTES (PIDDAC).

\section{References}

1. X. Maldague, Theory and practice of infrared technology for nondestructive testing (Wiley-Interscience Publication, USA, 2001)

2. D. Katunsky, A. Korjenic, J. Katunska, M. Lopusniak, S. Korjenic, S. Doroudiani, Building Environ 67 (2013)

3. J. Hart, A practical guide for infrared thermography for building surveys (BRE, UK, 2001)

4. C. Lerma, E. Barreira, R.M.S.F. Almeida, Energy Buildings 168 (2018)

5. F. Asdrubali, G. Baldinelli, F. Bianchi, Appl Energy 97 (2012)

6. E. Edis, I. Flores-Colen, J. Brito, Constr Building Mater 51 (2014)

7. C. Balaras, A. Argiriou, Energy Buildings 34, 2 (2002)

8. ISO 6781, Thermal Insulation-Qualitative detection of thermal irregularities in building envelopes-Infrared method (International Organization for Standardization, Switzerland, 1983)

9. E. Barreira, R.M.S.F. Almeida, J.P.B. Ferreira, Energy Procedia 132 (2017)

10. WUFI 2D (Fraunhofer - IBP Holzhirchen, 2008) 